Wit-Gele Kruis van Vlaanderen - University of Ghent Post Print

\title{
A Study of Core Interventions in Home Nursing
}

Kristel De Vliegher, Louis Paquay, Mieke Grypdonck, Renild Wouters, Roseline Debaillie, Ludo Geys

N.B.: When citing this work, cite the original article.

Original Publication:

De Vliegher, K., Paquay, L., Grypdonck, M., Wouters, R., Debaillie, R., Geys, L. (2005). A study of core interventions in Home Nursing. International Journal of Nursing Studies, 42, 513-520. 
Title:

A study of core interventions in Home Nursing

Journal: International Journal of Nursing Studies

Kristel De Vliegher

Nursing Department of the Wit-Gele Kruis van Vlaanderen, Brussels, Belgium

Louis Paquay

Nursing Department of the Wit-Gele Kruis van Vlaanderen, Brussels, Belgium, Academic Centre for General Practice, Katholieke Universiteit Leuven, Belgium

Prof. Dr. Mieke Grypdonck

University of Ghent, Ghent, Belgium

Renild Wouters

Nursing Department of the Wit-Gele Kruis van Vlaanderen, Brussels, Belgium,

Roseline Debaillie

Nursing Department of the Wit-Gele Kruis van Vlaanderen, Brussels, Belgium,

Ludo Geys

Wit-Gele Kruis van Vlaanderen, Brussels, Belgium

Kristel De Vliegher

Wit-Gele Kruis van Vlaanderen, Nursing Department

Frontispiesstraat 8, bus 1.2

1000 Brussels, Belgium

Tel.: 32.2.739.35.11

Fax: 32.2.739.35.99 


\section{ABSTRACT}

Aim: To gain insight into the core interventions in home nursing.

Methods: In this descriptive, quantitative, cross-sectional study two questionnaires, based on the Nursing Interventions Classification, were used to collect data from 501 nurses working in an organisation for home nursing in Belgium. Response rate was $88 \%$.

Results: The self-care assistance, (im)mobility and (psycho)social interventions are the most frequently performed interventions in home nursing, but they are performed and can only be interpreted in combination with other, more technical interventions. Therefore, these interventions can be considered the core interventions in home nursing.

Keywords: Core interventions, Home nursing, Nursing Interventions Classification

\section{INTRODUCTION}


Home nurses today have difficulty explaining their daily activities and the core of their profession to the general public and to health policy makers. Furthermore, little to no research has been conducted to support the home nurses in that debate. However, information about their daily activities and the core of the home nursing profession is very important and necessary in a financially restricted environment that focuses an effective and efficient management of health care.

In order to help home nurses explain their core activities we conducted a descriptive, quantitative, cross-sectional study of core interventions in home nursing in Belgium. In this study the concept of core interventions was defined as 'a limited, central set of interventions that defines the nature of the specialty' (McCloskey and Bulechek, 2000 pp.803).

This study of core interventions in home nursing has three purposes:

- to gain insight into the daily activities of home nurses and into the core interventions of home nursing;

- to be able to define the role of home nurses and the appreciation of the home nursing profession;

- to contribute to the discussion on 'a financing of the process of care' versus 'an achievement-oriented financing'.

\section{BACKGROUND}

\subsection{Related literature}

Nursing interventions receive much attention in the international literature. Some articles concern specific patient populations. For example Deal (1994) conducted a 
literature review to describe the types of services provided by community health nurses and to document the efficacy of community health nursing interventions. His main focus was to represent community health nursing strategies developed in response to the needs of high-risk families, geographic communities, and the vulnerable population groups and to demonstrate the effectiveness of home based and community-centred health nursing interventions. Boomsma et al. (1999) demonstrated, based on the Nursing Interventions Classification, the wide range of interventions nurses perform in both long-term and crisis-oriented psychiatric home care. In both types of psychiatric home care, medication management was the nursing intervention label to which most interventions related most closely.

Other studies focus on nursing classifications in which nursing interventions have their place, but they don't discuss core interventions in health care. For example Martin et al. (1993) conducted a study to provide descriptive data about the characteristics of home health clients, outcomes of care and nursing interventions, based on the Omaha System. Based on a sample of 2403 clients, the study showed that the nurses provided over 96000 interventions. In comparison with the Home Health Classification ( $\mathrm{HHC}$ ) and the Nursing Interventions Classification (NIC), the Omaha System is the oldest of the classifications, developed to meet the needs of community health nurses searching for alternatives in practice and documentation (Moorhead et al. 1993). The Home Health Classification, developed by Saba and colleagues, reflects the assessment and care of patients in the community setting (Moorhead et al. 1993) and is a method for classifying Home Health Medicare patients in order to predict resource requirements and to measure outcomes (Saba et al. 1991). 
McCloskey et al. (1998) performed a study with the focus not only on a nursing classification, but also on core interventions. However, the survey they developed was directed to clinical specialty organizations and not to the home healthcare. They mailed a survey to 49 clinical specialty organizations to identify the core interventions for the specialty using the Nursing Interventions Classification (NIC) terms. The top intervention, identified as core by 19 organizations, was Pain Management, closely followed by Documentation, Emotional Support and Discharge Planning (McCloskey et al. 1998).

We can conclude that little is known about the (core) interventions home nurses perform and about the most frequently performed interventions in home nursing. However, such information is very important to demonstrate to the general public and to health policy makers that the home nursing profession makes a difference.

\subsection{Nursing interventions and core interventions}

McCloskey and Bulechek (1997 pp.xxi) defined the term 'nursing intervention' as 'any treatment, based upon clinical judgment and knowledge, that a nurse performs to enhance patient/client outcomes'. This definition fits the purpose of the study.

McCloskey et al. (2000 pp.803) defined the concept of core interventions as follows: 'Core interventions are defined as a limited, central set of interventions that defines the nature of the specialty. A person reading the list of core interventions would be able to determine the area of specialty practice. The core set of interventions does not include all interventions used by nurses in the specialty, but rather includes 
those interventions that are used most often by nurses in the specialty or are used predominately by nurses in the specialty'.

\subsection{Nursing Interventions Classification}

The need for transparency into the daily activities of home nurses demands a uniform / standardized and comprehensive language which clearly demonstrates the contribution home nursing can make to healthcare.

A research team at the University of lowa, led by Joanne McCloskey and Gloria Bulechek, developed the Nursing Interventions Classification (NIC). The domains and classes provide a description of the essence of nursing. The language is comprehensive and can be used by nurses in all settings and in all specialties (McCloskey and Bulechek 2000). The NIC describes all interventions nurses perform on behalf of patients, including both independent and collaborative interventions. Although an individual nurse will have expertise in only a limited number of interventions, the entire classification is meant to capture the expertise of all nurses (Moorhead et al. 1993).

The NIC was used in this study for two reasons. Firstly, the NIC is a standardized, comprehensive classification, capturing all the interventions performed in home nursing. Secondly, home nurses, included in this study, are familiar with this classification and are receiving special training in the use of this classification, so it was better to give the participants a classification they were familiar with, rather than to introduce a new one.

The third edition of the NIC (McCloskey \& Bulechek, 2000) contains three levels. The highest and most abstract level contains 7 domains. Each domain is divided into 
classes. Each class contains a set of related interventions. The NIC contains 486 interventions each with a definition and a detailed set of activities to describe what it is a nurse does to implement the intervention.

For example: domain 3 'Behavioral' is divided into 6 classes and 68 interventions (for example, class 'Coping Assistance' and intervention 'Humor').

\subsection{Home nursing in Belgium}

In Belgium, professional home nursing is part of the social security system and is financed by the Federal Institute for the Insurance of Illness and Invalidity. Home nursing is reimbursed for patients who are insured, which is obliged in Belgium. For patients with low physical dependency the reimbursement concerns the interventions, which are included in the nomenclature of home nursing activities: bathing and hygienic care, injections, wound care, stoma care, blather care, vulva/vagina/airway care, gastro-intestinal care, replacement of a heparin lock (long term catheter) and specific technical nursing interventions like intravenous perfusion, subcutaneous perfusion, parenteral nutrition en epidural analgesia. All these interventions, with the exception of the intervention bathing, must be prescribed by a physician to be reimbursable. For patients with moderate to high physical dependency, global home nursing care is reimbursed by a fixed amount per day. It is important to realise that the type of interventions chosen and observed in the study reflect home nursing in Belgium.

\section{THE STUDY}




\subsection{Study objective}

The following research questions were defined to realise the three goals of this study:

1) Which interventions are most frequently performed in home nursing? (Registration)

2) Which interventions are, in the nurse's perception, most frequently performed in home nursing? (Subjective measure)

3) Is there a difference between the registered and the subjective frequency with which interventions are performed?

4) Which interventions are considered to be:

a. of high importance

b. of less importance

c. of no importance by home nurses?

5) Is there a (strong) relation between the registered frequency and the indicated importance attributed to the interventions?

6) Is there a (strong) relation between the subjective frequency and the indicated importance attributed to the interventions?

7) Which interventions can be considered the core interventions in home nursing?

\subsection{Method}

\section{Design/sample}

A descriptive, quantitative, cross-sectional study was conducted. Home nurses from three organisations for home nursing were included in the study: the White \& Yellow Cross, Solidarity of the Family and the National Federation of Services for Home Nursing from the Socialistic Mutuality in Flanders, Belgium. These three 
organisations form the Flemish Federation of Services for Home Nursing (about 5000 nurses). Home nurses were eligible to participate in the study if they were providing direct patient care and did not fulfil a management position and if they were able to understand, speak and read Dutch. The participants were recruited among organized home care services. Independent home nurses were not included. A random sample of 501 home nurses was drawn from an alphabetically ordered list of all personnel. The 501 home nurses received a letter explaining the purpose and the design of the study and the two questionnaires used in the study.

\section{Instruments}

A questionnaire was developed, as no instrument was found suitable for the study. The development of the questionnaires occurred in three phases. First, an expert panel reviewed the Nursing Interventions Classification for the relevance of the interventions to home nursing. The experts selected 271 interventions, relevant to home nursing.

Secondly, two questionnaires were developed based upon the selected 271 interventions from the Nursing Interventions Classification. The first questionnaire was designed to collect information about the frequency with which each intervention was performed over the past year and about the importance to home nursing attributed to each intervention. The nurses were asked to indicate the frequency of each intervention on a 12-point, ordinal scale. The highest frequency corresponded with 12 points on the scale (more than 10 times per day) and the lowest frequency with 1 point (1-5 times per year). A 3-point scale was used to indicate the importance of each intervention to the home nursing profession (of high importance $=3$; of less importance $=2$; of no importance $=1$ ). A description of high 
(specific to home nursing), less (not specific to home nursing, the intervention can also be performed by another discipline) and of no (this intervention is not performed by home nurses) importance was given in the instructions. The second questionnaire was designed to collect information about the patients cared for on a morning, afternoon or evening in the working week. The home nurses were asked to indicate for each patient which of the interventions they had carried out. Non listed interventions could be added in free text. Instructions were added to help the nurses complete the questionnaires. Demographic variables of the participants and of the patients were also included in the questionnaires.

Finally, twenty-nine home nurses, who were not part of the larger study, tested the questionnaires. This resulted in some minor changes in the instructions and in the addition of one intervention (a total of 272 interventions).

\section{Ethical issues}

The executive board of each of the three participating organisations for home nursing gave access to the nurses, working in these organisations, to participate in the study. Written informed consent was obtained from the participating nurses. The information about the patients, given by the nurses, was obtained anonymously.

\section{Data collection}

The respondents received the questionnaires by mail with stamped self-addressed envelopes. In order to improve the response rate, a follow-up letter was sent to all participants who did not return their questionnaires after three weeks. The study was conducted from February 2002 until March 2002. 


\section{Data analysis}

The questionnaires were scanned with the software package Teleform 7.0. The Statistical Package for the Social Sciences (SPSS) 9.0.1 was used for data analysis. Frequency tables were used to gain insight into the frequency with which interventions were performed in home nursing and into the interventions that were considered most important for the home nursing profession (research questions 1-24). Pearson correlations were used to examine the relation between the registered frequency, the subjective frequency and the indicated importance attributed to the interventions (research questions 3-5-6). The core interventions were examined using Multidimensional Scaling (MDS) (research question 7). "MDS is a set of mathematical techniques. These techniques use proximities among any kind of objects as input. A proximity is a number which indicates how similar or how different two objects are, or are perceived to be, or any measure of this kind. The main output is a spatial representation, consisting of a geometric configuration of points, as on a map. Each point in the configuration corresponds to one of the objects. The configuration of points reflects the 'hidden structure' in the data and often makes the data much easier to comprehend. By reflecting the data structure it means that the larger the dissimilarity (or the smaller the similarity) between the two objects, as shown by their proximity value, the further apart they should be in the spatial map. In this study, to get proximities from data that are not proximities and hence inappropriate for MDS in their original form is to compute some measure of profile similarity or dissimilarity. To derive a profile proximity measure correlations were computed. A dimensional interpretation of the configuration is the most common approach used in MDS. Sometimes structure can be observed in the multidimensional space in addition to or instead of that provided by a dimensional 
interpretation (neighbourhood interpretation). (Kruskal et al. 1978)". MDS obtains the underlying dimensions from respondents' judgements about the similarity of products (interventions). It does not require a list of attributes to be shown to the respondents. This is an important advantage of MDS.

\section{RESULTS}

A total of 441 home nurses (response rate=88\%) completed and returned the questionnaires. Some respondents failed to provide all the necessary demographic details of themselves and the patients they concluded in the study. The respondents had a mean age of 35.9 years $(n=440), 96.8 \%$ was female $(n=$ $440)$ and their mean years of service was $12(n=439)$. The majority of the respondents worked part-time $(66.1 \% ; n=440)$.

To complete the second questionnaire the respondents were asked to choose a day of the week and a moment of that day that would give a richness of information about their daily activities: $45.5 \%$ of the respondents chose a Monday $(n=426)$ and $89.3 \%$ chose a morning $(n=423)$.

All 441 respondents completed the first questionnaire, but three respondents stated that is was too time consuming to complete the second questionnaire as well. Data about 6764 patients were gathered in the second questionnaire $(n=438)$. This adds up to an average of 15 patients per respondent. The majority of these patients were female $(65 \% ; n=6476)$ and their mean age was 73.8 years $(n=6460)$.

4.1 Frequency and importance of interventions (research questions 1-2-4) 
The top 10 of most frequently performed interventions according to the nurse's perception, together with the top 10 of interventions most frequently carried out by home nurses and the top 10 of the most important interventions to the home nursing profession are shown in table 1 . The interventions are ranked from most to least frequent / important. With regard to the interventions most frequently registered, the interventions are ranked according to the number of times an intervention was registered (sum). With regard to the nurse's perception of frequency and the importance, the interventions are ranked according to the mean score (mean). The interventions bathing and clothing are the two most frequently performed interventions and the intervention pressure ulcer care received the highest importance score.

\subsection{Consistency (Research questions 3-5-6)}

Generally, there was a high correlation between the frequency, according to nurse's perception, and the importance assigned to the interventions (Pearson Correlation 0.86, 95\% C.I. 0.83-0.89). The technical interventions were higher ranked (cf. table 1) than the (psycho)social interventions. There was also a high correlation between the registered frequency and the frequency according to the nurse's perception (Pearson Correlation $0.81,95 \%$ C.I. $0.77-0.84$ ). This finding is somewhat surprising because psychosocial interventions were higher ranked according to the registered frequency. The frequency of the registered interventions and the importance of the interventions correlated significantly lower (Pearson Correlation 0.60, 95\% C.I. 0.55$0.65)$.

\subsection{Core interventions (Research question 7)}


The choice was made to use a 3-dimensional representation of the interventions. Three dimensions allowed structuring the data in an adequate way and the stress value (0.22) did not decrease much with a higher number of dimensions. Figure 1 shows the 3-dimensional representation. Each number represents an intervention (from 1 to 272) and each colour represents a category of interventions (cf. table 2). The interventions in the central cloud are projected there because they correlate very high with all the other interventions. This means that these central interventions need to be interpreted in combination with the interventions surrounding this cloud. MDS approached the data individually (interventions level). The interventions can also be approached from the classes whereto they belong in the Nursing Interventions Classification (class level): aggregation of data. Figure 2 shows the aggregation of the data for the intervention bathing (the most frequently performed intervention). The number of times this intervention was performed in home nursing (3812) was equated with $100 \%$. The figure shows that $96 \%$ of the patients, who received help with bathing, received other interventions from the class 'self-care assistance' as well. The percentage of $96 \%$ was calculated without the intervention bathing. The intervention bathing seems to be frequently performed in combination with interventions from the classes 'coping assistance' and 'skin/wound management'.

\section{DISCUSSION}

\subsection{Frequency of the interventions}


According to the nurse's perception and to the registration of interventions, the interventions bathing and clothing were the two interventions most frequently performed in home nursing. Generally, the self-care assistance interventions (bathing, clothing, hair care) and the (im)mobility (top 20) interventions (positioning, transport, energy management) were indicated and registered as most frequently performed with patients.

The registration of interventions also showed that the (psycho)social interventions (presence, active listening, humour, interventions regarding teaching, family care and collegiality) were frequently performed in home nursing. However, these (psycho)social interventions were considered to be less frequently performed over the past year than the more technical interventions (medication administration, gastro-intestinal care, breathing management, circulation care, urinary care). This could be due to the fact that the more technical interventions are included in the nomenclature of the Federal Institute for the Insurance of IIIness and Invalidity (Belgian finance system). This nomenclature contains the interventions that have to be registered and reported for reimbursement for financial reasons. Thus, the home nursing organization receives financing for the performed technical interventions, but not for the (psycho)social interventions.

\subsection{Importance of the interventions}

Technical interventions and the interventions in life threatening situations were indicated as most important. Psycho(social) interventions, with the exception of the collegiality interventions, were considered less important. This finding raises the question whether the evaluation was influenced by the importance of the interventions to the patients, instead of the importance to the home nursing 
profession. Further research is required to gain a clearer insight in the importance of the interventions performed by home nurses.

\subsection{Consistency}

The interventions bathing and clothing, together with other self-care assistance interventions and (im)mobility (top 20) interventions, were registered as most frequently performed in home nursing and also indicated by the participants as most frequently performed. However, these interventions were not considered the most important ones to the home nursing profession. Technical interventions and collegiality interventions were found to be more important. This indicates that the most frequently performed interventions did not correspond with the interventions which were considered most important to the home nursing profession.

\subsection{Core interventions}

In comparison with a dimensional interpretation (to look for lines/dimensions in the configuration, possibly at right angles to each other, such that the projection at opposite extremes of a line differ from each other in some easily describable way (Kruskal 1978), a neighbourhood interpretation of the configuration of points seemed to be the best way to gain insight into the core interventions in home nursing. Thus, the interpretation was mainly directed towards discovering the meaning of the interventions far and close to one another.

The central cloud is characterized by self-care assistance interventions (bathing and clothing included), (im)mobility and (psycho)social interventions (including interventions regarding prevention, teaching, family and system enhancement and collegiality interventions). The more technical interventions are situated around the 
central cloud. It is obvious that the central cloud contains almost no pure technical interventions. In particular, the self-care assistance interventions, (im)mobility and (psycho)social interventions can be considered to be the core interventions in home nursing: they were not performed as separate interventions, but always in combination with the other, more technical interventions. This means that when a home nurse performs a set of interventions, it is likely that one or more of the interventions, indicated as core interventions, are included.

The aggregation of data gave a clear representation of the activities of the nurses, but the MDS representation was far more detailed (interventions versus classes of interventions). This technique of aggregating the data supported the findings with MDS: the self-care assistance interventions, (im)mobility and (psycho)social interventions were mostly performed in combination with other (more technical) interventions.

\subsection{Limitations of the study}

Home nurses were asked to indicate the importance of each intervention for the home nursing profession. However, it is possible that the participants judged the importance of the interventions from the patient's point of view instead of the point of view of the home nursing profession. For example, the intervention 'resuscitation' was registered as very important and from the point of view of the patient, it indeed is, but this intervention was not frequently performed in home nursing. Thus, further research is necessary regarding the importance of performed interventions. The subject of this study is very important to home nurses. They often feel that the general public simplifies their daily activities to 'bathing of patients'. Thus, it is possible that the participants gave answers that best defended their profession. 
A study of the international literature showed that little is known about the core interventions in home nursing. This makes it very difficult to compare the findings in this study with other similar studies in home nursing. For example, the study of Boomsma et al. (1999) showed the wide range of interventions nurses perform in psychiatric home care. This finding corresponds well with the findings in this study, but in psychiatric home care medication management interventions were most frequently performed, which was not the case in this study. The study of McCloskey

et al. (1998) showed that pain management, documentation, emotional support and discharge planning were the interventions most frequently performed in 19 clinical specialty organizations. However, this study showed that self-care assistance interventions, (im)mobility interventions and (psycho)social interventions were most frequently performed in home nursing. Thus, the results of this study should not be generalised to other health care settings or countries. Nevertheless, all health care settings and countries are confronted with and influenced by a fast evolving social, demographic and economic landscape, which makes it necessary for health care in general to put the focus on effective and efficient management and on the ability of each healthcare setting to define their contribution to the health and autonomy of clients. Therefore, this study is an important step towards transparency and clarity into the daily activities of home nurses.

\section{CONCLUSION}

It is shown that of the interventions for which healthcare financing provides a reimbursement, only the interventions bathing, medication administration and wound care are frequently performed. Thus, the current financing system does not fit the 
actual work of home nurses. This study can contribute to establishing a better system.

This study is also an important step towards transparency of the daily activities of home nurses. This study makes it obvious that home nurses perform several interventions simultaneously, that all the aspects of care are important in home nursing and that the activity profile of home nurses is not only defined by more technical interventions. This implicates a different approach of the home nursing profession: somatic care and non-somatic care go hand in hand. Thus, performing the intervention bathing includes a complex set of interventions.

\section{ACKNOWLEDGEMENTS}

The authors would like to acknowledge the authority of the Belgian Federal Ministry of Social Affairs, Public Health and the Environment for their financial and intrinsic support. We would also like to acknowledge Geert Beheydt, English lecturer at 
Ehsal, Brussels and Susan Broekmans, assistant at the Catholic University of Leuven, Belgium, for proofreading the article.

\section{REFERENCES}

Albersnagel, E., van der Brug, Y., 1997. Diagnoses, resultaten en interventies. Wolters, Noordhoff. 
Arnaert, A., Delesie, L., 1999. IJking van meetgegevens: RIZIV A.D.L.-index. Acta Hospitalia 4, 19-31.

Boomsma, J., Dassen, T., Dingemans, C., Van den Heuvel, W., 1999. Nursing interventions in crisis-oriented and long-term psychiatric home care. Scandinavian Journal Caring Science 13, 41-48.

Deal, L.W., 1994. The effectiveness of community health interventions : a literature review. Public Health Nursing 11, 315-323.

De Boeck, P., Rosenberg, S., 1988. Hierarchical classes: model and data analysis. Psychometrika 53, 361-381.

De Pelsmacker, P., Van Kenhove, P., 1994. Marktonderzoek. Methoden en toepassingen. Garant, Leuven/Apeldoorn.

Gastmans, C., Dierckx de Casterlé, B., 2000. Verpleegkundige excellentie: Verpleegkunde tussen praktijk en ethiek. Elsevier, Maarssen.

Geys, L., Van Loon, H., 1989. Wat voeren verpleegkundigen uit in de thuisverpleging? Frequentie van verpleegkundige handelingen in het Wit-Gele Kruis. Concepten en cijfers ter financiering van de thuisverpleging. Nationale Federatie van Wit-Gele Kruisverenigingen, Brussel. 
Gordon, M., 1999. Verpleegkundige diagnostiek: Proces en toepassing. Elsevier / De tijdstroom, Maarssen.

Kruskal, J.B., Wish, M., 1978. Multidimensional Scaling: Sage University Papers, Series 07-011 (Quantitative Applications in the Social Sciences Series). Sage, London.

Lang, N., Clark, J., 1992. Nursing's next advance: an international classification for nursing practice. International Nursing Review 38, 109-112.

Martin, K.S., Scheet, N.J., Stegman, M.R., 1993. Home health clients: characteristics, outcomes of care and nursing interventions. American Journal of Public Health 83, 1730-1734.

McCloskey, J.C., Bulechek, G.M., 1997. Verpleegkundige interventies. De Tijdstroom, Utrecht.

McCloskey, J.C., Bulechek, G.M., Donahue, W., 1998. Nursing interventions core to specialty practice. In Handboek verpleegkundige diagnostiek, interventies en resultaten (McCloskey J.C. \& Bulechek G.M.), Mosby, St. Louis, pp. 803-805. McCloskey, J.C., Bulechek, G.M., 2000. Nursing Interventions Classification (NIC) (3rd ed.). Mosby, St. Louis.

Mendonck, K., Meulemans, H., 2000. Tijd voor zorg: Een analyse van de zorgverlening in de gezondheids- en welzijnssector. VUBpress, Brussel. 
Moorhead, S.A., McCloskey, J.C., Bulechek, G.M., 1993. Nursing Interventions Classification: A comparison with the Omaha System and the Home Health Care Classification. JONA 23, 23-29.

Redes, S, Lunney, M., 1997. Validation by school nurses of the nursing intervention classification. Computers in Nursing 15, 333-338.

Saba, V.K., O'Hare, P.A., Zuckerman, A.E., Boondas, J., Levine, E., Oatway, D.M., 1991. A nursing intervention taxonomy for home health care. Nursing \& Health Care 12, 296-299.

Swanborn, P., 1993. Schaaltechnieken. Boom, Amsterdam.

Tacq, J., 1992. Van probleem naar analyse. De keuze van een gepaste multivariate analysetechniek bij een sociaal-wetenschappelijke probleemstelling. Academisch Boeken centrum, De Lier.

Ten Napel, H., van der Brug, Y.M., 1996. Vooronderzoek Verpleegkundige Interventies, classificaties en definities. Copywright WCC, Zoetermeer. Van Mechelen, I., De Boeck, P., 1995. The conjunctive model of hierarchical classes. Psychometrika, 60, 505-521. 
Figure 1(before discussion, p. 16): Projection of the interventions into a 3-dimensional space

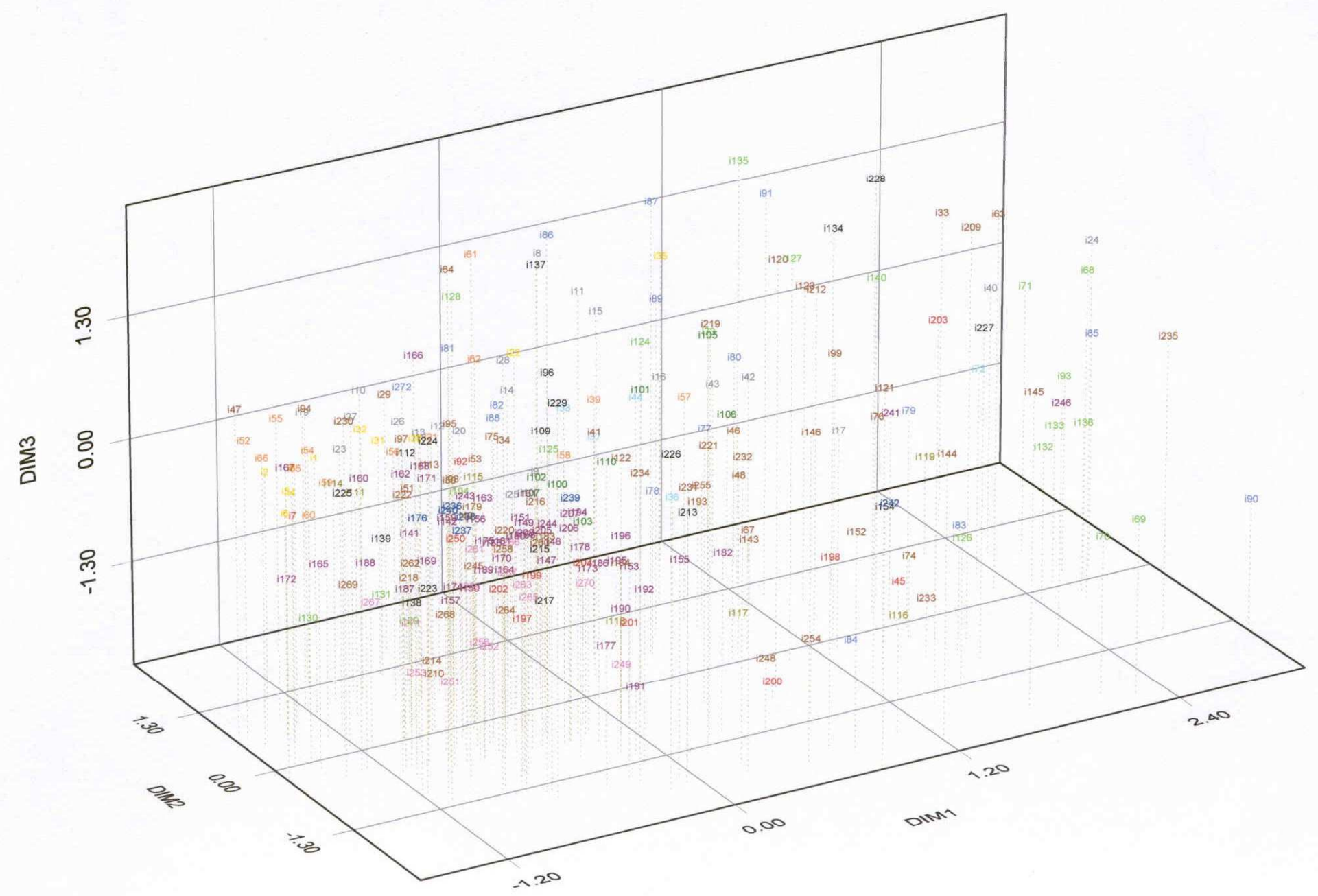


Figure 2 (p. 16): Aggregation of data for the intervention 'Bathing'

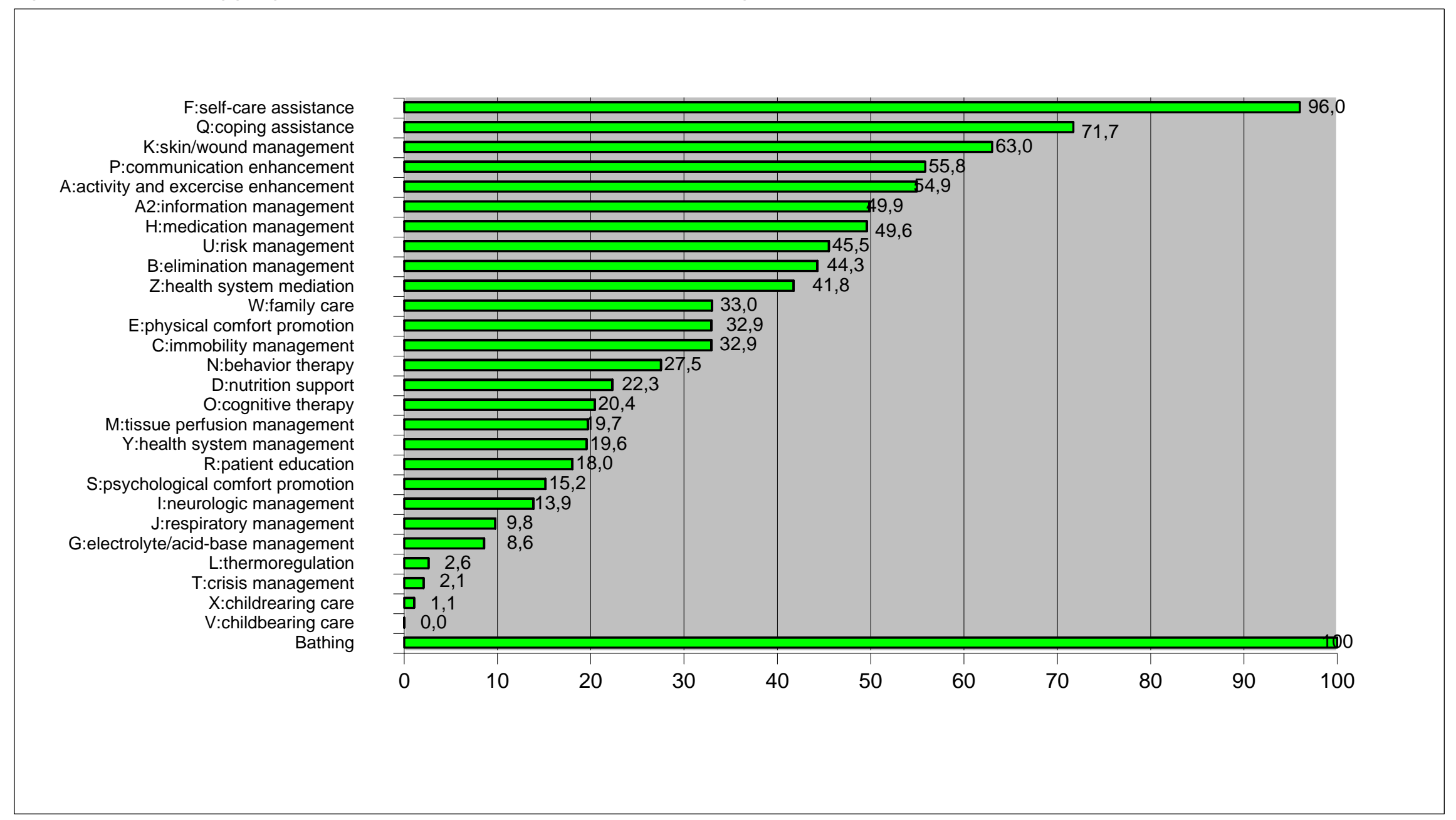


Table 1 (before 'Consistency', p. 15): Ranking the interventions from most frequently performed and most important to least frequently performed and least important (Sum, Mean, N, SD)

\begin{tabular}{|c|c|c|c|c|c|c|c|c|c|c|c|c|c|c|c|}
\hline & \multicolumn{5}{|c|}{ Objective frequency } & \multicolumn{5}{|c|}{ Subjective frequency } & \multicolumn{5}{|c|}{ Importance } \\
\hline Rank & Int. & Sum & $N$ & Mean & $S D$ & Int. & Mean & $N$ & Sum & $S D$ & Int. & Mean & $N$ & Sum & $S D$ \\
\hline 1 & Bathing & 3812 & 438 & 8.7 & 3.39 & Bathing & 10.45 & 438 & 4578 & 1.98 & $\begin{array}{c}\text { Pressure ulcer } \\
\text { care }\end{array}$ & 2.99 & 428 & 1278 & 0.12 \\
\hline 2 & Clothing & 3509 & 438 & 8.01 & 3.11 & Clothing & 10.19 & 437 & 4451 & 2.04 & $\begin{array}{c}\text { Medication } \\
\text { administration } \\
\text { (IM) }\end{array}$ & 2.98 & 439 & 1310 & 0.14 \\
\hline 3 & Presence & 3285 & 438 & 7.5 & 5.29 & Skin care & 9.38 & 422 & 3960 & 2.04 & Shift report & 2.98 & 433 & 1291 & 0.15 \\
\hline 4 & Foot care & 3132 & 438 & 7.15 & 3.92 & $\begin{array}{l}\text { Pressure ulcer } \\
\text { prevention }\end{array}$ & 9.33 & 433 & 4040 & 2.00 & Woundirrigation & 2.98 & 411 & 1224 & 0.15 \\
\hline 5 & Active listening & 3001 & 438 & 6.85 & 5.17 & Foot care & 9.31 & 433 & 4030 & 1.94 & $\begin{array}{c}\text { Surgical wound } \\
\text { care }\end{array}$ & 2.97 & 434 & 1290 & 0.16 \\
\hline 6 & Hair care & 2170 & 438 & 4.95 & 3.53 & Presence & 9.19 & 410 & 3767 & 2.89 & Wound care & 2.97 & 433 & 1287 & 0.18 \\
\hline 7 & $\begin{array}{l}\text { Skin care: topical } \\
\text { treatments }\end{array}$ & 2132 & 438 & 4.87 & 3.37 & Active listening & 9.18 & 413 & 3793 & 2.70 & $\begin{array}{l}\text { Physician co- } \\
\text { operation }\end{array}$ & 2.97 & 431 & 1279 & 0.18 \\
\hline 8 & Nail care & 2005 & 438 & 4.58 & 3.88 & $\begin{array}{c}\text { Pressure } \\
\text { management }\end{array}$ & 9.05 & 430 & 3893 & 2.00 & Report & 2.97 & 421 & 1249 & 0.19 \\
\hline 9 & Shift report & 2000 & 438 & 4.57 & 5.23 & Perineal care & 9.00 & 415 & 3735 & 2.74 & $\begin{array}{c}\text { Medication } \\
\text { administration } \\
\text { (SC) }\end{array}$ & 2.96 & 430 & 1274 & 0.19 \\
\hline 10 & Perineal care & 1991 & 438 & 4.55 & 3.97 & $\begin{array}{c}\text { Medication } \\
\text { administration } \\
\text { (SC) }\end{array}$ & 8.99 & 428 & 3847 & 2.25 & Ostomy care & 2.96 & 412 & 1219 & 0.22 \\
\hline
\end{tabular}


Table 2 (Before discussion, p. 16): Survey of the colours representing a category

\begin{tabular}{||l|l||}
\hline Colour & Category \\
\hline Black & Precautions and prevention interventions \\
\hline Red & Teaching interventions \\
\hline Rose & Collegiality interventions \\
\hline Brown & General care interventions \\
\hline Light green & Circulation and fluid-electrolyte interventions \\
\hline Dark green & Breathing interventions \\
\hline Kaki & Skin and wound care interventions \\
\hline Purple & (Psycho)social interventions \\
\hline Turquoise & Support feeding interventions \\
\hline Light blue & Medication administration interventions \\
\hline Dark blue & Family and system enhancement interventions \\
\hline Orange & Self-care assistance interventions \\
\hline Gray & Gastro-intestinal interventions \\
\hline Yellow & (Im)mobility interventions \\
\hline
\end{tabular}

